EPJ Web of Conferences 114,02127 (2016)

DOI: $10.1051 /$ epjconf/201611402127

(C) Owned by the authors, published by EDP Sciences, 2016

\title{
Passive heating of the ground surface
}

\author{
Anna Tyburczyk $k^{1, a}$ \\ ${ }^{1}$ Kielce University of Technology, 25-314 Kielce, Al. 1000-lecia P.P. 7, Poland
}

\begin{abstract}
The phenomenon of phase change is one of the most important contemporary issues of thermal engineering. In particular, this applies to all kinds of heat exchanger systems, which should achieve the highest possible efficiency while reducing investment and operating costs. Some of these systems are heat pipes or thermosyphons, which, among others, are used for the heat transfer, temperature stabilization and the regulation of heat flux density. Additionally, they are passive systems, and therefore do not require an external power supply. Heat pipes can be used to stabilize the surface temperature of roads and driveways. Large heat tubes can be applied for heating the surface of bridges and overpasses, which become icy in unfavorable climatic conditions. The paper presents research on the test facility, whose main component is a long vertical copper fin. The temperature at the base of the fin was kept constant for a given series of measurements. Heat receiving fluid was ethanol at atmospheric pressure. The measurement methodology and the results of investigations were discussed. The surface temperature distribution was measured with the infrared camera, and on this basis the local values of heat flow and the heat transfer coefficient were determined. The results were presented as boiling curves for both the fin with the smooth surface and the one covered with a metal capillary-porous structure. The results obtained are useful in the design of heat exchangers, including passive heating of the ground.
\end{abstract}

\section{Introduction}

The phenomenon of phase change in economy sectors is one of the most important contemporary issues of thermal engineering. It refers in particular to different kinds of exchanger systems, which should achieve the highest possible efficiency while reducing investment and operating costs.

Regarding this, it is advisable to pay attention to systems based on heat tubes, which are used i.a. in heat transfer, temperature stabilization and the regulation of heat flux density. In the construction industry they are applied in solar collectors, heat exchangers, wall heating systems and radiant wall panels.

Heat tubes or heat pipes [1,2] are simple devices without movable parts, filled with a working fluid and the vapours of this fluid. They can successfully transport large amounts of heat over long distances with a nearly constant temperature along the length. In addition, their effective operation requires no external energy supply, as opposed to other exchangers where the flow of the agent is forced by the operation of the pump or fan.

The heat pipe, schematically shown in figure 1 , is a slender tube lined with a structure designed with carefully selected geometrical/physical parameters, containing small amounts of a pressurized fluid, whose boiling temperature is selected in view of the heat exchange conditions [3].

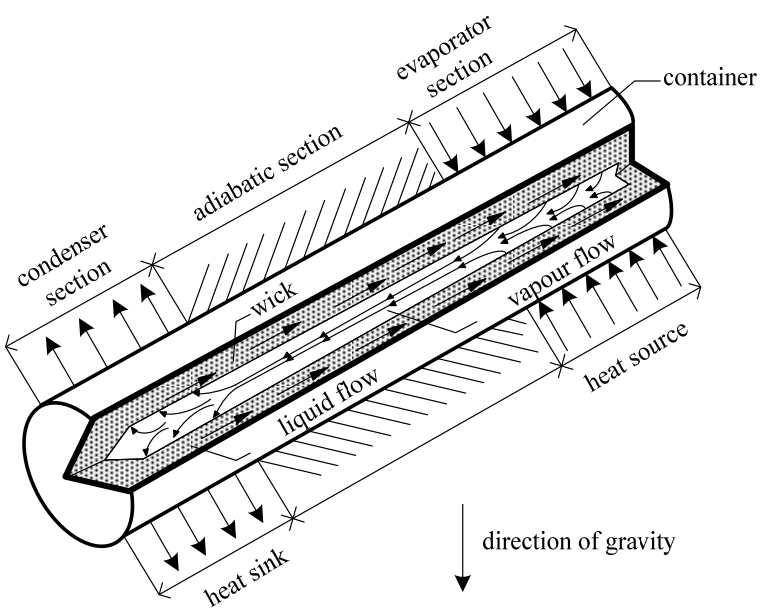

Figure 1. Diagram of a typical heat pipe with a schematic principle of operation

Heat pipes can be divided primarily with regard to the way in which the condensate is transported to the evaporator. One can distinguish here thermosyphons, rotating heat pipes and tubes with capillary structures in

\footnotetext{
a Corresponding author: annazw@tu.kielce.pl
} 
which the transport of the condensate occurs as a result of capillary pressure.

Owing to the capillary-porous filling, heat pipes can work both in horizontal and vertical position. The reason for this is the high value of capillary forces as compared to the forces of gravity. A greater efficiency of such systems can be achieved by maximizing the capillary forces, with the research in this area focused on the use of various kinds of porous fillings [4].

One of the simplest and most common methods of developing the surface is the application of mesh structures such as the metal-fiber or powder ones, including those that are thermally sprayed [5]. The metalfiber capillary-porous and mesh structures are of special interest in this group [6]. Metal-fiber coverings are made of thin fibers of various metals and their alloys. Careful application of such structures results in a high value of the heat transfer coefficient, with appropriately selected parameters such as thickness, porosity and skeletal conductivity. Mesh structures are commercially available and capable of forming capillary-porous structures with desired geometrical parameters, defined by volume porosity and height.

Inside the heat pipe a capillary-porous lining is applied, performing various functions depending on the location. One end thereof is an evaporator in which the fluid evaporation occurs as a result of absorbing heat from the surrounding environment. The condensation combined with heat emission to the surrounding atmosphere occurs at the opposite end. The operation of exchangers equipped in heat tubes is limited by crisis phenomena [7]. Excessive overheating of the evaporator results in the stagnation phenomenon, and restarting the operation is associated with lowering the surface temperature, which proceeds in film boiling conditions.

Transport and construction industry take advantage primarily of heat tubes with capillary structures [8]. They are used for:

- ground temperature stabilization around foundations and supports in arctic areas,

- defrosting of icy roads,

- the preparation of domestic hot water in heat exchangers,

- accumulation of solar energy in solar collectors,

- wall and underfloor heating,

- heating ventilation air in combination with ecological energy sources.

Heat pipes have also been used to stabilize the temperature of the road surface [9]. For example, during the construction of the railway between China and Tibet they were placed in the permafrost sections. During thaw the ground under the railway sleepers thawed, which resulted in the collapsed tracks and broken rails. For these reason the pipes were designed to transfer the heat in one direction only, i.e. from the ground to the environment. The condensing section of the tubes was finned and projected above the surface of the ground, where it emits the heat extracted from the ground to the air. This caused the lowering of the ground temperature, which remains negative even during the thaw.
A similar solution was applied in the construction of the pipeline which transports oil from the north to the south of Alaska. A number of heat pipes that protect the ground from thawing and prevent pipe damage were installed along the route of the pipeline.

In the Nordic countries heat tubes are used for heating the road [10]. They are installed directly beneath the road surface to maintain a constant, positive temperature of asphalt. Such solutions take advantage of geothermal energy available throughout the year [11], which can be accumulated to cover the peak demand [12].

Another application of large-size heat pipes is using them for heating the surface of bridges and overpasses, which in unfavorable climatic conditions become icy [13]. Such a system operates as a thermosyphon, where the supplied heat is associated with the convection movement. In this case there is no need for capillaryporous layer between the section of the evaporator and the condenser, as the liquid phase condensed in the upper part flows down to the evaporator by gravity [14].

There are two types of solutions available here: passive and active systems. The passive system is the one in which the evaporator section is inserted in the ground at the depth where the temperature is constantly above $0^{\circ} \mathrm{C}$. By contrast, the condenser section is placed directly under the surface, which should be protected from freezing. It is worth noting that this system further lowers the carrier temperature of the roadway in summer, increasing its durability. A simplified diagram of such a system is shown in figure 2. This system works spontaneously, without further supply of energy, which advantageously reduces the cost of operation $[15,16]$.

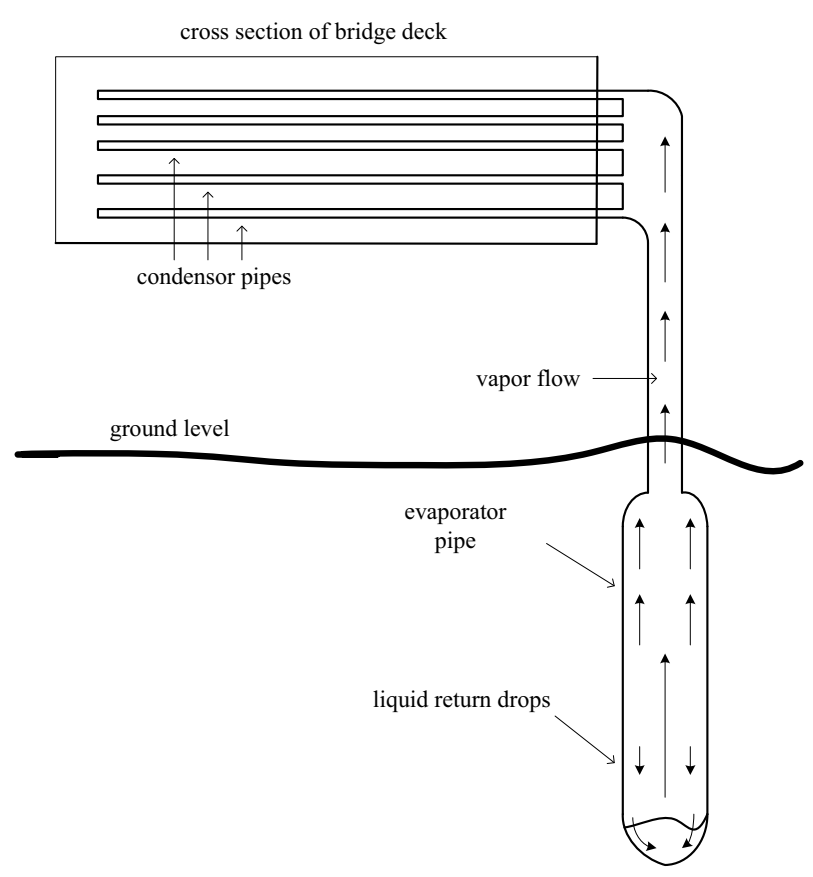

Figure 2. Diagram of the passive system of heating ground surface

In active systems operating with an external heat source e.g. a boiler, the systems equipped with heat pipes 
provide the stabilization of temperature, its fine adjustment and the reduction of the maximum value (see figure 3).

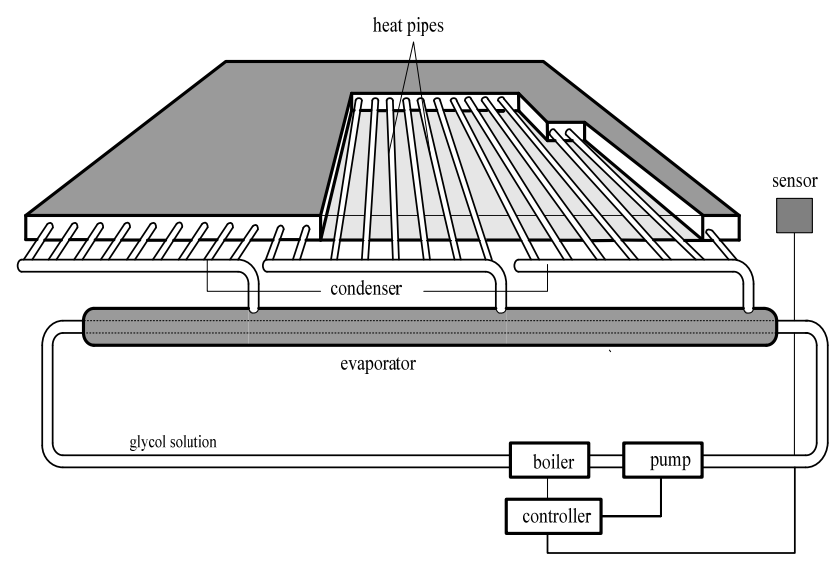

Figure 3. Active system diagram. Ground heating system that uses heat tubes and glycolic indirect system

The objective of this paper is to analyze the heat exchange at the boiling of ethanol as illustrated by nonisothermal surface of a long copper fin coated with one layer of mesh and metal-fiber capillary-porous structure with the predetermined microstructure parameters.

\section{Test facility}

The tests were conducted on the stand, whose simplified diagram is presented in figure 4 .

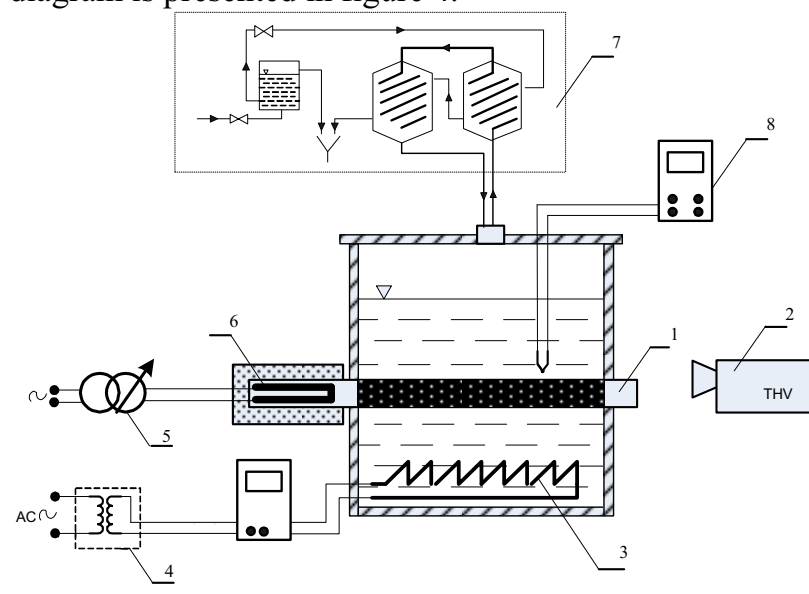

Figure 4. Diagram of the test facility for non-isothermal samples 1 - the examined element, 2 - the thermovision camera, 3 - the auxiliary heater, 4 - the separation system with the control of supplied electric power, 5 - the main heater system with the electric power measurement, 6 - the main heater, 7 - the liquid supply and condensate recovery system, 8 - temperature measurement and control system

Its main part is a flat fin with a rectangular cross section. It is mounted between two side bakelite plates, which provide a housing for the container filled with a boiling liquid. The fin is one-sidedly covered with the structure intensifying the heat exchange (mesh layer with the metal-fiber capillary-porous structure) on the side of the liquid. The tests were performed in stationary conditions at the set temperature, different, however, for each series of measurements at the base of the fin. The necessary heat was supplied by the main electric heater powered from the autotransformer. In order to maintain boiling throughout the vessel, the auxiliary heater system was applied, with the heating part in the form of a resistance wire placed spirally at the bottom. Constant electric power supplied in the auxiliary heater system was maintained for all the measurement series. The vapour cooling and the condensate recovery were performed in a separate system of two radiators whose temperature was stabilized with district heating water in an open system.

The object of measurement is the surface temperature distribution across the fin from the outside, which was measured with an infrared camera VarioCAM ${ }^{\circledR}$ hr. The camera is equipped with an uncooled bolometric matrix with the $640 \times 480$ pixels image format. The device is designed to work in a long-wave range of infrared radiation of $7.5 \div 14 \mu \mathrm{m}$. The study was conducted with a standard camera lens $(30 \times 23)^{\circ}$. The studied surface was evenly covered with black paint in order to ensure the optical uniformity of the outer surface of the tested samples.

The assembled measuring system permits assuming a single-dimensional phenomenon, i.e. the assumption that the change in temperature in relation to the fin thickness is negligibly small. This assumption is valid for the numbers of $\mathrm{Bi}<0.1$ [17]. The result of the study is a onedimensional temperature distribution alongside the length of the fin along its axis.

Real objects emit not only their own, but also reflected radiation [18], which have a large impact on the final outcome measure [19]. Correct temperature reading requires an individual determination the emissivity of the investigated facility [20]. Therefore, before starting the measurement, calibration was performed examined surface radiation properties.

\section{Research results and methodology}

The tests were performed for a copper sample. A mesh structure with a metallic-fiber capillary-porous layer of the following parameters: height $\mathrm{h}_{\mathrm{w}}=0.8 \mathrm{~mm}$ and a volume porosity of $\sim 65 \%$ was sintered on the sample. The structure was made from cut wire with the diameter of $0.05 \mathrm{~mm}$ and the fiber length of $\sim 3 \mathrm{~mm}$, sintered in reducing hydrogen atmosphere [21]. Ethanol at atmospheric pressure was the heat-receiving agent. For comparative and calibration purposes a copper fin with a smooth surface was tested in identical conditions [22].

The thermal field was obtained with the help of an infrared camera as a result of examining the outer surface of the analyzed part.

Figure 5 shows an example of a post-axial temperature distribution along the studied fin at the constant power of the main heater for two samples: the one with the smooth surface and the one coated with a mesh and capillary-porous structure. The Figure below shows that the application of the fibrous coating enhances the heat exchange as compared to a smooth surface. Due 
to a correspondingly large size, the cooling to the liquid boiling temperature occurs below the half-height point of the sample. This is observed for all the measurement series performed at a different electric power levels applied at the base of the main heater.

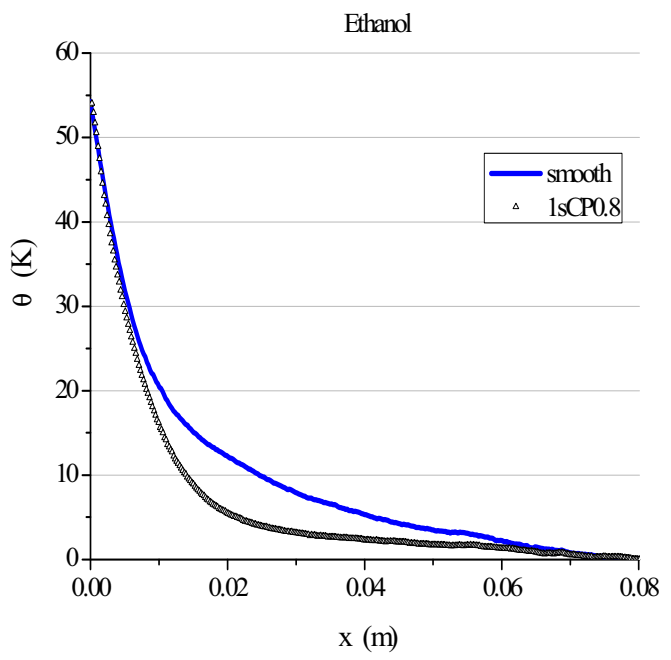

Figure 5. Temperature distribution on the copper fin along the center line at the constant power of the main heater for a smooth and capillary-porous sample with a layer height of 0.8 $\mathrm{mm}$

The use of the infrared camera for measurement results in a large number of measurement points, permitting the application of the numerical differentiation combined with smoothing. Using this method, a derivative for the two examined samples, presented in figure 6 , was determined with respect to the fin length. It is proportional to the amount of the transposed heat along the length of the element.

It should be noted that the value of the derivative is almost zero at a point below the half-height of the fin.

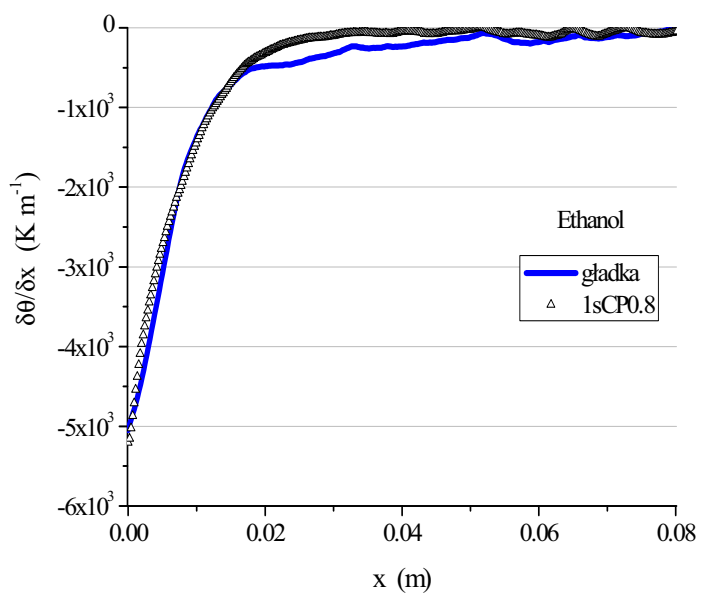

Figure 6. Temperature gradient versus length for the smooth sample and the sample coated with a single mesh layer with the capillary-porous structure

The derivative shown in figure 6 is used to calculate the locally transferred heat fluxes, and consequently to determine the boiling curve for the analyzed element with a non-isothermal surface. The result of the calculations for the smooth sample and the sample coated with mesh with the capillary-porous structure is presented in figure 7. The detailed calculation procedure is described in the paper [23].

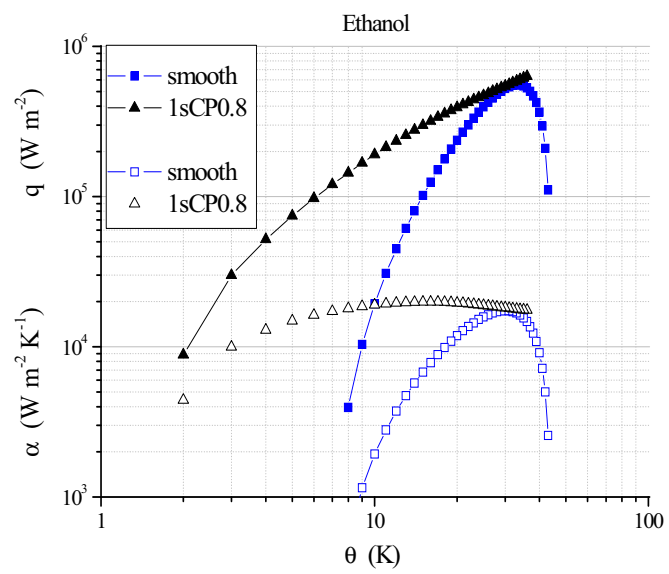

Figure 7. Boiling curve for the smooth sample and the sample coated with a mesh structure with a metallic-fibrous capillaryporous layer

\section{Conclusions}

The final result of the conducted research is the relation of the locally transferred fluxes and the heat transfer coefficients for fins: with a smooth surface and with mesh and capillary-porous coating. As shown in diagram 7 nucleate pool boiling starts at the superheating of $\sim 8 \mathrm{~K}$ for a smooth surfaced sample and at only $\sim 2 \mathrm{~K}$ for a sample with a structural coating. A similar shift towards lower values of overheating is observed for maximum values of heat flux. Table 1 contains local values of heat flux density at constant superheating. The difference between those values was calculated for both samples. While the difference initially grows, it decreases for higher values of superheating. The maximum difference is noted in the case of $14 \mathrm{~K}$ superheat, for which $\Delta \mathrm{q}=\mathrm{q}_{\text {capillary-porous }}-\mathrm{q}_{\text {smooth }}=197.3 \mathrm{~kW} \mathrm{~m}^{-2}$.

Tab. 1. Heat flux density at constant superheating

\begin{tabular}{|c|c|c|c|c|c|}
\hline $\begin{array}{c}\mathrm{q} \\
\left(\mathrm{kW} \mathrm{m}^{-2}\right)\end{array}$ & $\begin{array}{c}\theta=10 \\
(\mathrm{~K})\end{array}$ & $\begin{array}{c}\theta=14 \\
(\mathrm{~K})\end{array}$ & $\begin{array}{c}\theta=19 \\
(\mathrm{~K})\end{array}$ & $\begin{array}{c}\theta=26 \\
(\mathrm{~K})\end{array}$ & $\begin{array}{c}\theta=29 \\
(\mathrm{~K})\end{array}$ \\
\hline $\mathrm{Q}_{\text {smooth }}$ & 19.3 & 80.3 & 206.9 & 425.0 & 502.8 \\
\hline $\begin{array}{c}\mathrm{Q}_{\text {capillary- }} \\
\text { porous }\end{array}$ & 190.0 & 277.6 & 374.3 & 487.1 & 530.7 \\
\hline $\mathbf{\Delta q}$ & $\mathbf{1 7 0 . 7}$ & $\mathbf{1 9 7 . 3}$ & $\mathbf{1 6 7 . 4}$ & $\mathbf{6 2 . 1}$ & $\mathbf{2 7 . 9}$ \\
\hline
\end{tabular}

\section{References}

1. D. Reay, A. Harvey, Appl. Therm. Eng., 57 (2013)

2. L.L. Vasiliev, Appl. Therm. Eng., 25 (2005)

3. H.N. Chaudhry, B.R. Hughes, S.A. Ghani, Renew. Sust. Energ. Rev., 16 (2012)

4. T.M. Wójcik, EPJ Web of Conferences, 25 (2012)

5. M.G. Semena, A.N. Geršuni, V.K. Zaripov, Višč. Škola, Kiev, 1984

6. R. Pastuszko, EPJ Web of Conferences, 45 (2013) 
7. T. Orzechowski, S. Wciślik, Int. J. Heat Mass Tran., 73 (2014)

8. T.S. Wiśniewski, Wymiana ciepła, WNT, Warszawa, 1995

9. http://en.sunpower.com.cn/, [online 15.06.2015]

10. http://www.alyeska-pipeline.com/, [online 15.06.2015]

11. A. Manzella, Geothermal energy, EPJ Web of Conferences, 98 (2015)

12. T. Orzechowski, K. Stokowiec, COW, 44/1 (2013)

13. http://www.smartbridge.okstate.edu/, [online 15.06.2015]

14. P. Jakóbowski, TChiK, 4 - 5 (2009)

15. A. Nurpeiis, EPJ Web of Conferences, 76 (2014)

16. P. Nemec, A. Čaja, M. Malcho, EPJ Web of Conferences, 45 (2013)

17. I.L. Pioro, W. Rohsenow, S.S. Doerffer, Int. J. Heat Mass Tran., 47 (2004)

18. T. Kruczek, Energy, 91 (2015)

19. T. Kruczek, Energy, 62 (2013)

20. T. Orzechowski, Exp. Therm. Fluid Sci., 31 (2007)

21. T. Orzechowski, A. Zwierzchowska, S. ZwierzchowskA, Inż. Ap. Chem., 6 (2009)

22. T. Orzechowski, A. Zwierzchowska, S. Zwierzchowska, 8-th European Conference of Young Research and Scientific Workers, 2009

23. T. Orzechowski, Exp. Therm. Fluid Sci., 8 (2007) 